\title{
Vascular factors and metabolic interactions in the pathogenesis of diabetic neuropathy
}

\author{
N. E. Cameron ${ }^{1}$, S.E.M.Eaton ${ }^{2}$, M.A.Cotter ${ }^{1}$, S. Tesfaye ${ }^{2}$ \\ ${ }^{1}$ Department of Biomedical Sciences, Institute of Medical Sciences, University of Aberdeen, Aberdeen, Scotland, \\ United Kingdom \\ ${ }^{2}$ Diabetes Centre, Royal Hallamshire Hospital, Glossop Road, Sheffield, United Kingdom
}

\section{Abstract}

Diabetes mellitus is a major cause of peripheral neuropathy, commonly manifested as distal symmetrical polyneuropathy. This review examines evidence for the importance of vascular factors and their metabolic substrate from human and animal studies. Diabetic neuropathy is associated with risk factors for macrovascular disease and with other microvascular complications such as poor metabolic control, dyslipidaemia, body mass index, smoking, microalbuminuria and retinopathy. Studies in human and animal models have shown reduced nerve perfusion and endoneurial hypoxia. Investigations on biopsy material from patients with mild to severe neuropathy show graded structural changes in nerve microvasculature including basement membrane thickening, pericyte degeneration and endothelial cell hyperplasia. Arterio-venous shunting also contributes to reduced endoneurial perfusion. These vascular changes strongly correlate with clinical defects and nerve pathology. Vasodilator treatment in patients and animals improves nerve function. Early vasa nervorum functional changes are caused by the metabolic insults of dia- betes, the balance between vasodilation and vasoconstriction is altered. Vascular endothelium is particularly vulnerable, with deficits in the major endothelial vasodilators, nitric oxide, endothelium-derived hyperpolarising factor and prostacyclin. Hyperglycaemia and dyslipidaemia driven oxidative stress is a major contributor, enhanced by advanced glycation end product formation and polyol pathway activation. These are coupled to protein kinase $\mathrm{C}$ activation and $\omega-6$ essential fatty acid dysmetabolism. Together, this complex of interacting metabolic factors accounts for endothelial dysfunction, reduced nerve perfusion and function. Thus, the evidence emphasises the importance of vascular dysfunction, driven by metabolic change, as a cause of diabetic neuropathy, and highlights potential therapeutic approaches. [Diabetologia (2001) 44: 1973-1988]

Keywords Diabetic neuropathy, nerve conduction, nerve pathology, blood flow, ischaemia, microangiopathy, vascular endothelium, nitric oxide, oxidative stress, protein kinase $\mathrm{C}$, advanced glycation, aldose reductase.
Received: 19 March 2001 and in revised form: 15 June 2001

Corresponding author: N. Cameron, Department of Biomedical Sciences, Institute of Medical Sciences, Institute of Medical Sciences, University of Aberdeen, Foresterhill, Aberdeen AB25 2ZD

Abbreviations: ACE, angiotensin converting enzyme; AGE, advanced glycation end product; ARI, aldose reductase inhibitor; DSP, distal symmetrical polyneuropathy; eDHF, endothelium derived hyperpolarising factor; $\mathrm{NCV}$, nerve conduction velocity; NO, nitric oxide; $\mathrm{PG}$, prostaglandin; $\mathrm{PKC}$, protein kinase $\mathrm{C}$
Hyperglycaemia is a fundamental metabolic insult in diabetes mellitus, due to either a relative or absolute deficiency of insulin. However, hyperglycaemia alone cannot completely explain the complications of diabetes. Intensive blood glucose control dramatically reduces microvascular complications but does not prevent them altogether $[1,2]$. The current optimal management of microvascular disease can only attempt to control glycaemia and then to deal with the complications when they occur. Consequently, patients continue to go blind, develop renal failure and 
undergo lower extremity amputations making a greater understanding of the pathogenesis of microvascular disease to enhance the development of rational therapies urgent.

Distal symmetrical polyneuropathy (DSP) is probably the most common but least understood of the microvascular complications of diabetes [3]. This review will discuss the pathogenesis of DSP and the complex vascular and metabolic interactions involved.

\section{Diabetic distal symmetrical polyneuropathy}

Diabetes mellitus can predispose to a variety of neurological syndromes, DSP being the most common [4-6]. DSP is a length-dependent sensory and motor neuropathy, with sensory loss starting in the toes and spreading into the legs and hands in a "stocking and glove" distribution. Sensory symptoms and signs predominate, usually sensory loss and numbness. However, some patients also suffer painful or "positive" symptoms, which can be extremely distressing and difficult to treat $[7,8]$. The involvement of the motor system is usually sub-clinical in the early stages of DSP although it is easily detectable by neurophysiological testing and can become disabling as the disease progresses [9]. Autonomic dysfunction also is usually present and can be manifested in a variety of ways including postural hypotension, gastrointestinal dysmotility or erectile dysfunction [6]. Progressive axon degeneration affects all fibre types and teased fibre studies show demyelination $[10,11]$, indicating a combined insult on axons and Schwann cells.

Diabetes mellitus is the leading cause of peripheral neuropathy in the western world [12]. In the past, there have been wide variations in reported prevalence rates of DSP [13], however, with improved consensus as to the definition of DSP and better standardisation of neurophysiological tests, several recent large epidemiological studies have consistently reported rates around $30 \%[14,15]$. The most important clinical sequalae of sensory loss is foot ulceration, the most common cause of hospital admission in diabetic patients and the leading cause of non-traumatic lower limb amputations $[12,16]$. Consequently, DSP is important not just on clinical grounds but also on economic grounds, particularly because the prevalence of diabetes continues to increase dramatically $[17,18]$. To understand the pathogenesis of DSP more clearly, to allow the development of effective treatments to prevent, slow, or even reverse the disease process is therefore more and more important.

\section{Pathogenesis of distal symmetrical polyneuropathy}

An understanding of the pathogenesis of DSP has been obfuscated in the past by polarised views as to whether metabolic or vascular factors were more important. However, current opinion focuses on the existence of complex interactions between the two at all stages of disease. Indeed, microvascular reactivity is impaired and agonist-stimulated endothelium-dependent vasodilation can be compromised before the onset of frank hyperglycaemia in those at risk of developing Type II (non-insulin-dependent) diabetes mellitus $[19,20]$. The association of DSP with macrovascular and other microvascular diseases highlights the role of vascular factors.

Neuropathy and risk factors for macrovascular disease. Several studies have shown the association of DSP with risk factors that predict the development of macrovascular disease. Hypertension has been implicated as a strong risk factor for DSP [14, 21, 22]. In the United Kingdom Prospective Diabetes Study (UKPDS), control of hypertension not only markedly improved macrovascular outcomes but also reduced microvascular complications. Furthermore, two small trials with angiotensin converting enzyme (ACE) inhibitors and one using another vasodilator, the $5 \mathrm{HT}_{2}$ antagonist sarpogrelate, have shown nerve conduction velocity (NCV) improvements in DSP [23-25]. Other important risk factors for DSP include cigarette smoking, dyslipidaemia, microalbuminuria and BMI $[14,26]$. Many of these factors are already treated aggressively in diabetes and this could consequently also benefit peripheral nerve. However, evidence from a recent trial on the effects of aggressive risk factor control showed benefits for nephropathy, retinopathy and autonomic neuropathy but not peripheral neuropathy [27].

Association with other microvascular disease. There is a clear vascular aetiology for retinopathy and nephropathy. The strong association between these complications and DSP indicate a common pathogenic mechanism [14]. The retina allows direct visualization of the vasculature and has therefore been studied extensively. It used to be thought that retinal blood flow is increased initially, followed by hypoperfusion and hypoxia, all occurring before any effect on retinal function is evident [28]. However, more recent studies, backed by data from animal models, show that the very earliest insult is a fall in retinal perfusion [29]. Subsequently, there are maladaptive interactions with trophic factors such as vascular endothelial growth factor and poor metabolic control, which eventually cause proliferation of unstable vessels and the development of potentially sight-threatening diseases [30, 31]. Studies of renal perfusion have also shown that blood flow initially increases before any functional defect is apparent [32]. This is followed by a gradual decline in glomerular perfusion and consequently filtration and renal function. It is still not completely clear whether hyperperfusion precedes 
blood flow reductions in the peripheral nerve, although the majority of experimental evidence from humans and animal models suggests this is not the case [33-35]. The microvasculature of the eye, kidney and nerve might not be directly comparable because there might be different autoregulatory, cytokine and trophic mechanisms governing both normal responses and those to insults such as hyperglycaemia and hypoxia.

\section{Experimental studies of microvascular disease in human distal symmetrical polyneuropathy}

Endoneurial blood flow and hypoxia. The cardinal features of in vivo studies of the sural nerve in established human DSP are hypoxia and reduced nerve blood flow (Fig. 1). Microelectrode polarography first demonstrated reduced sural nerve endoneurial oxygen tension in DSP[36]. Recently, less invasive techniques have been developed allowing intracapillary haemoglobin oxygen saturation to be measured using microlightguide spectrophotometry and have confirmed hypoxia in DSP [37]. Nerve blood flow, estimated using fluorescein angiography, is markedly reduced and correlates strongly with neurophysiological parameters and intracapillary oxygen saturation $[37,38]$. Interestingly, non-neuropathic diabetic patients had blood flow and oxygen saturation values that were intermediate to, but not markedly different from, the control subjects and neuropathic patients suggesting some degree of microvascular disease in this group [37]. Studies evaluating early, subclinical neuropathy using these techniques have not yet been reported.

One study examined nerve blood flow in early DSP using laser-Doppler flowmetry [39]. The limitations of the study include the use of disease controls (rather than non-neuropathic diabetic and healthy control subjects), the difficulty of measuring blood flow by laser-Doppler and this technique's lack of specificity in monitoring nutritive perfusion [40]. However, the study showed similar values for laserDoppler flux in early DSP and other neuropathies, whereas there were reductions in vasculitic neuropathy [39]. Although the authors argue that these results suggest that blood flow might not be reduced in early mild human DSP, this issue requires further evaluation using more robust and accurate techniques for assessing nerve perfusion.

There is strong indirect evidence that hypoxia has a role in nerve dysfunction. Reduced transcutaneous oxygen tension is associated with reductions in peroneal motor NCV [41]. Peripheral vascular disease can exacerbate neuropathy [42], an effect which can be partially reversed by surgical reconstruction of the diseased arteries [43]. Nerve conduction velocity increases in normal nerves with exercise, due to increased nerve perfusion, but does not rise in DSP
[44]. Furthermore, peripheral neuropathy can develop in non-diabetic subjects with chronic hypoxia, for example in chronic obstructive pulmonary disease. Neuropathological changes were similar to those found in DSP [45], suggesting that hypoxia without the complex metabolic derangement of diabetes is sufficient to cause neuronal dysfunction.

Increased resistance to ischaemic conduction failure has been described in both DSP and hypoxic neuropathy $[46,47]$ and refers to the enhanced ability of nerves to maintain function, assessed by NCV or persistence of sensation, when the blood supply is occluded. The cause of this phenomenon is not clear although it could be an adaptive change to chronic hypoxia and indeed, the effect is reversed by oxygen supplementation [47]. A similar phenomenon has been noted in animal models. Hyperglycaemia might make a partial contribution, presumably by increasing nerve energy substrate availability [48]. However, the finding that vasodilator treatment can reduce the development of ischaemic resistance, and in non diabetic rats, ischaemic resistance can be produced when nerve vascular supply is compromised by chronic partial blockade of endothelium-dependent vasodilation indicates a vascular component $[49,50]$.

Structural changes and nerve vasculature. The fact that structural vascular disease can have a role in the pathogenesis of neurological damage in diabetes has been recognized for over 100 years [51]. The first specific linkage of diabetic peripheral neuropathy with microvascular disease came from the thickening and hyalinisation of the intraneural vessel wall [52]. This has subsequently been shown to be due to a thickening and reduplication of the capillary basal lamina [53-55]. Sural nerve biopsy studies and the development of detailed ultrastructural techniques have allowed further assessment of the nerve fibre and accompanying microvascular pathologies. Endoneurial microangiopathy has been consistently seen in both mild and chronic DSP, with similar, but markedly less severe changes in diabetic patients without neuropathy [55-58]. The pathological changes (Fig. 2) include capillary basement membrane thickening, pericyte degeneration and endothelial cell hyperplasia and have been shown to correlate strongly with the degree of nerve fibre and clinical defect [55-60]. Interestingly, the abnormalities are more severe in endoneurial capillaries than in the epineurium, skin and muscle indicating a complex intraneural neurovascular interaction [61]. The cause of these abnormalities is not clear. Basement membrane thickening has been observed in hereditary sensory and motor neuropathy and could therefore represent a response to nerve damage [62]. However, basement membrane thickening and endothelial cell hyperplasia could also be a maladaptive response to hypoxia causing reduced diffusion capacity, therefore exacerbating the hypoxia. 

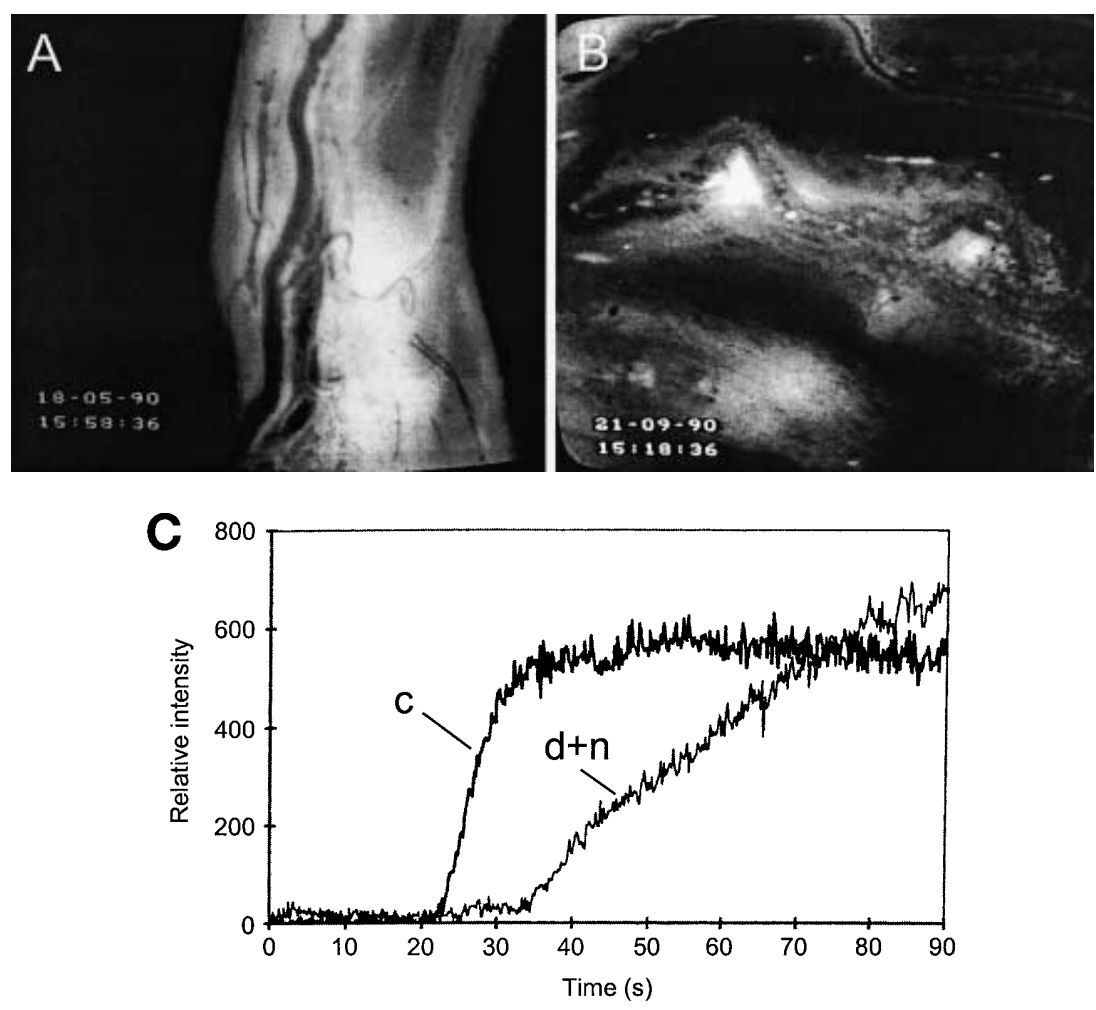

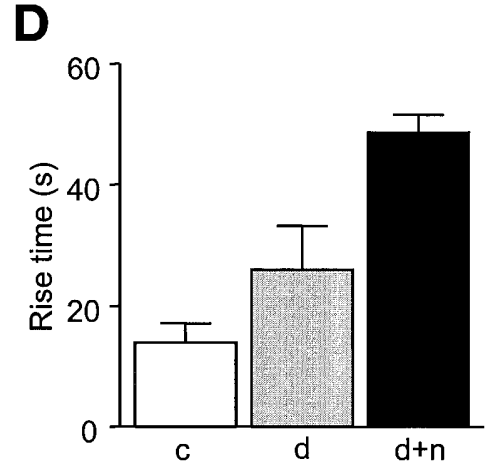

Fig.1A-E. Sural nerve fluorescein angiograms from a nonneuropathic diabetic subject (A) showing normal intensity of fluorescence and a subject with chronic neuropathy (B) showing a reduction in fluorescence due to impaired blood flow. The time course of the appearance of fluorescence $(\mathbf{C})$ was slowed in a neuropathic diabetic subject $(d+n)$ compared to a non-diabetic control subject (c), indicating impaired nerve blood flow. This was reflected in the fluorescein rise time (D) for groups of non-diabetic control $(c ; n=9)$, non-neuropathic diabetic $(\mathrm{d} ; n=9)$ and neuropathic diabetic $(\mathrm{d}+\mathrm{n} ; n=10)$ patients. The mean sural nerve intravascular oxygen saturation (E) was reduced in diabetic patients with chronic neuropathy, strongly correlating with the increase in fluorescein rise time. Fig. 1A-C reproduced with permission $[39,40]$

The role of capillary luminal area and vessel occlusion remains controversial. Several groups have demonstrated endothelial hyperplasia, leading to reductions in luminal area [63-66]. This, in conjunction with haemorheological abnormalities including fibrin
E

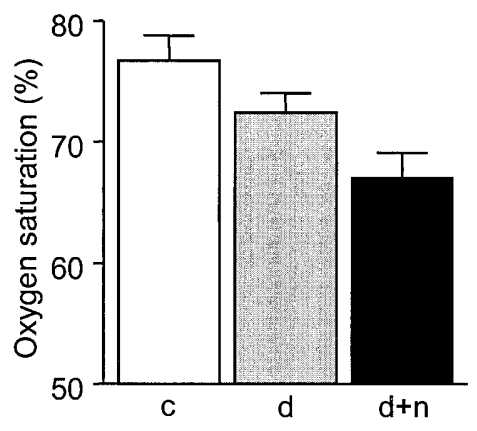

deposition [65], platelet activation [67] and erythrocyte aggregation [68-70] could cause vessel occlusion and endoneurial hypoxia [70,71]. Indeed, the degree of neuropathy was closely correlated with the numbers of closed vessels [66]. More recently however, the contrary finding of increased endoneurial capillary luminal area in DSP has been reported, indicating that this could be an adaptive change to endoneurial hypoxia [72].

Unmyelinated nerve fibres participate in the regulation of endoneurial blood flow by controlling arterio-venous shunting in the epineurial and perineurial feeding arterioles [73]. Damage to these fibres occurs early in the neuropathic process and this loss of controlling innervation can exacerbate endoneurial hypoxia [74]. The potential contribution of arterio-venous shunting to DSP has been identified by a number of groups. The observation of dilated veins and bounding arterial pulses in DSP and the increases in $\mathrm{pO}_{2}$ in the foot veins indicated arterio-venous shunt- 


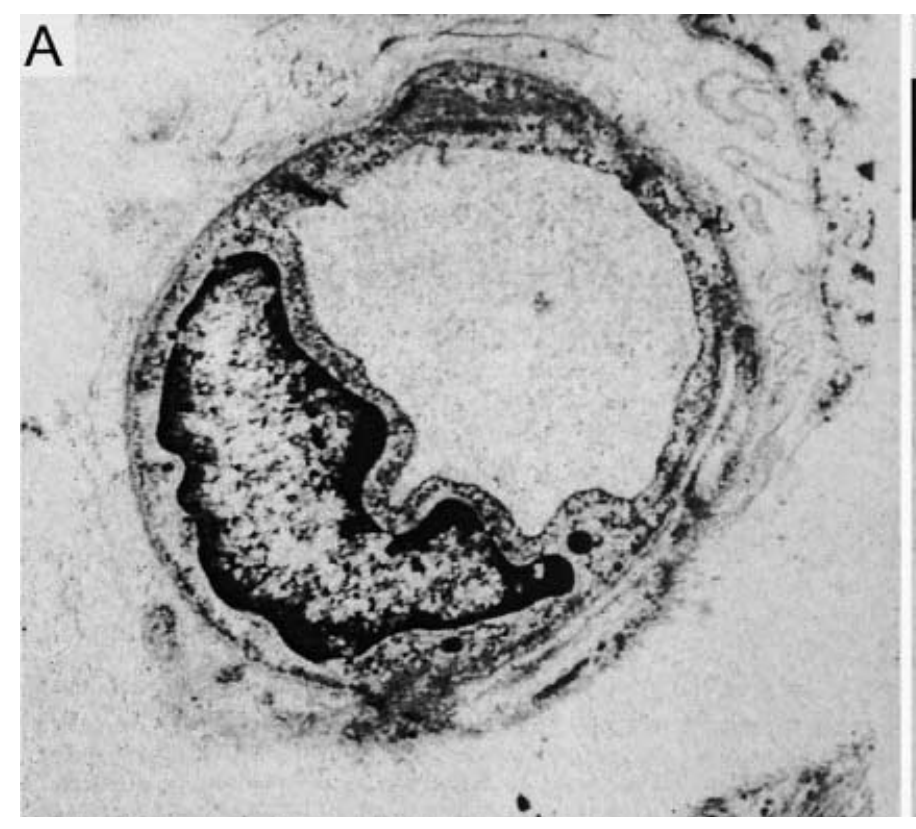

Fig. 2 A, B. Photomicrographs of endoneurial capillaries from sural nerve biopsies showing (A) a normal capillary from a diabetic patient without neuropathy and $(\mathbf{B})$ a closed capillary from a subject with diabetic neuropathy, with basement membrane (BM) thickening and endothelial cell (e) proliferation. Photomicrographs courtesy of Dr. R. A. Malik, University of Manchester, Manchester UK

ing at the skin [75]. Interestingly, arterio-venous shunting has been shown on the surface of the sural nerve in DSP (Fig. 3) as well as acute painful neuropathy of rapid glycaemic control, implying endoneurial hypoxia $[38,76]$.

Role of ischaemia in nerve fibre pathology. It is not clear whether the nerve fibre pathology described in human DSP can be explained by ischaemia. Indeed, the symmetrical, length-dependent nature of DSP has been used as argument against a vascular pathology. Certainly, the insult required to cause neurological dysfunction in DSP is likely to be considerable, as the nutritive blood supply is extensive and anastomotic. In experimental studies only patchy ischaemia is induced by ligation of localised nutrient arterioles [77]. Microsphere embolisation studies showed that many microvessels had to be occluded before sizeable nerve fibre damage occurred [78]. However, post-mortem and teased fibre studies in humans have shown that proximal multifocal vascular lesions can summate to produce distal fibre loss [11] which was used to argue that ischaemia was the primary cause. Furthermore, neuronal lesions in autopsy studies of DSP were very similar to those of non-diabetic subjects with vasculitis [79]. Thus, there is clear evidence that the microangiopathic process is extensive and could be sufficient to explain the pathologic data.

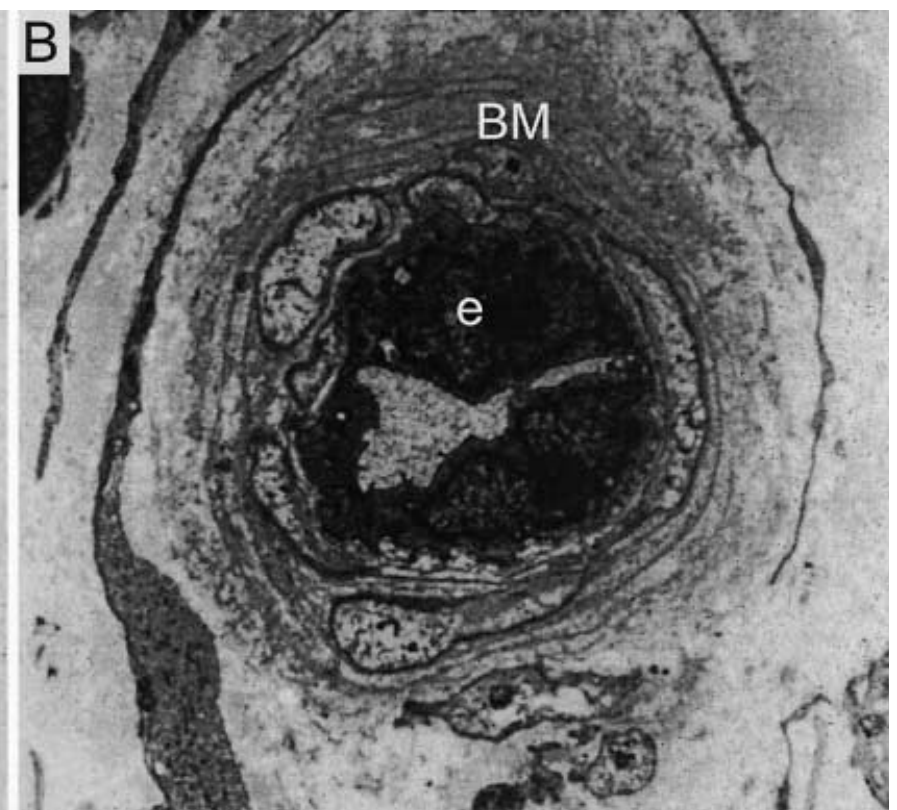

\section{Specific diabetic neuropathic conditions in man and the role of vascular factors}

Painful neuropathies. Further evidence that hypoxia plays a role in neuronal dysfunction comes from specific manifestations of neurological damage in diabetes. A proportion of patients with DSP will develop painful symptoms and, although many of the pathogenic mechanisms can be the same, the cause of this pain has to be considered [7]. Acute painful neuropathy of rapid glycaemic control, so-called "insulin neuritis", has a very different presentation and prognosis to DSP [76]. Extensive epineurial vessel abnormalities were apparent including arterio-venous shunting as seen in DSP. However, there was also evidence of new vessel growth on the surface of the nerve (Fig. 4) which had features similar to retinal neovascularisation [76]. The cause of these neural new vessels is not clear although they have been strongly linked in the retina to hypoxia and a variety of growth factors [31]. Consequently, it was suggested that the hypoxia could be driving the pain. In animal studies, acute intravenous insulin infusion (in the absence of hypoglycaemia) promoted the opening of nerve arterio-venous shunts in diabetic and non-diabetic rats, which diverted blood from the nerve capillary bed causing reduced endoneurial oxygen tension [80].

Recently nerve blood flow and intracapillary oxygen saturation have been compared in patients with DSP with and without painful symptoms, and higher blood flow and less hypoxia was observed in those patients with pain [81]. It is not clear whether this represents a general hyperperfusion of the nerve or further profound arterio-venous shunting from the endoneurium but the distinct differences between patients with and without pain strongly suggests that haemodynamic factors are important. 

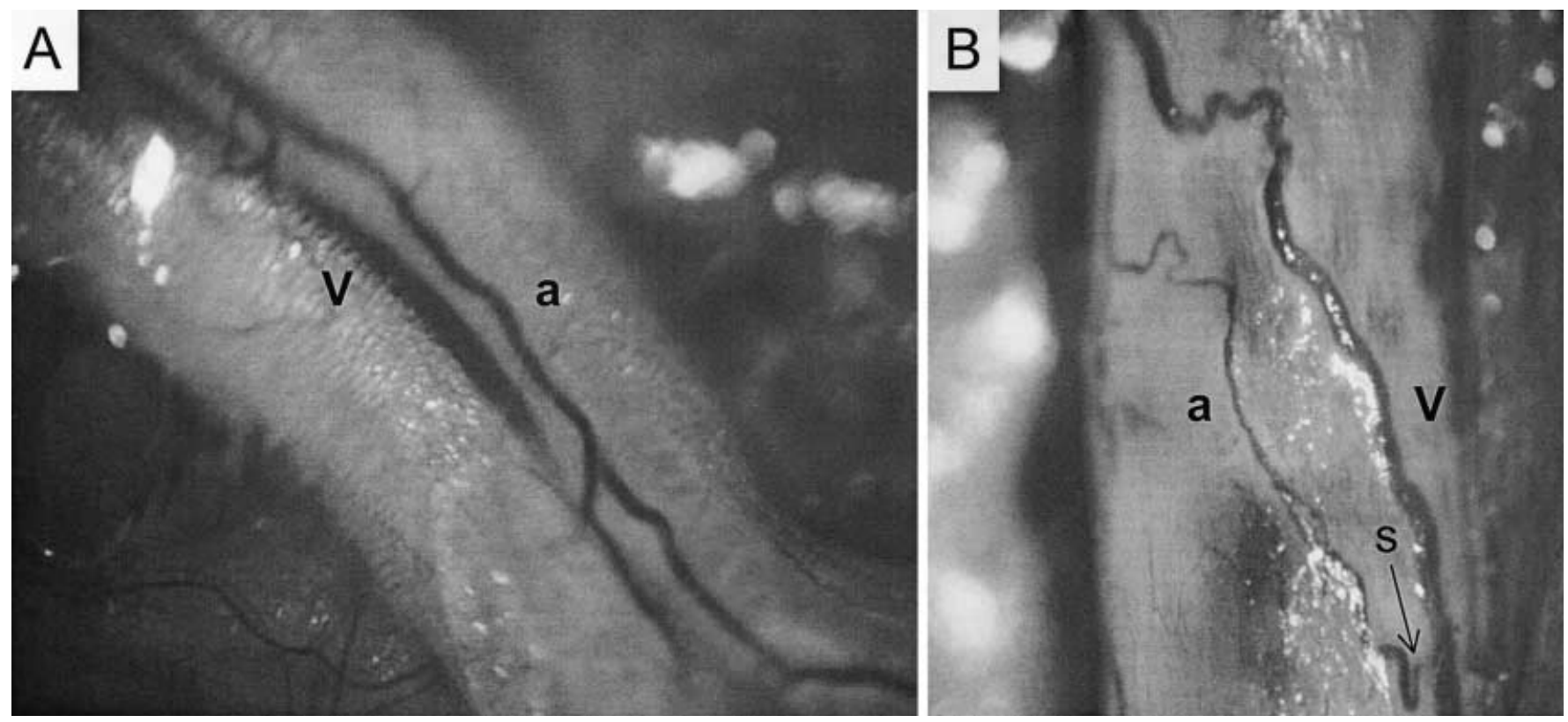

Fig. 3 A, B. Surface view of the sural nerve from a non-diabetic subject (A) showing normal arterial (a) and venous (V) anatomy. This contrasts with findings for a patient with chronic diabetic neuropathy (B), where there was arterial (a) attenuation, venous (V) tortuosity and arterio-venous shunting (s). Reproduced with permission [40]

Mononeuropathies. Perhaps the neurological syndromes with the strongest evidence of an ischaemic origin are the mononeuropathies. Histological studies in third cranial nerve palsy have revealed localised infarcts within the nerve and its nuclei $[82,83]$. A single, focal ischaemic insult is indeed suggested by the clinical features of this condition particularly its abrupt onset, good prognosis and pupillary sparing, which presumably occurs as the peripherally placed parasympathetic fibres have a separate blood supply [84].

\section{Commonly used animal models of distal symmetrical polyneuropathy}

Frequently used animal models consist of chemicallyinduced (alloxan and streptozotocin) or genetically diabetic rodents. All nerve fibre types are affected, although the early abnormalities normally studied are functional ones, such as reduced NCV and increased ischaemic resistance, and at best are accompanied by subtle rather than gross morphometric alterations and fibre degeneration $[85,86]$. Early apoptosis-like changes have also been reported for neuronal cell bodies in dorsal root ganglia [87]. In the long term, degenerative changes occur in motor and sensory fibres, roughly analogous to those in patients
[88-91]. In these models, although deficits are symmetrical, the nerves are too short for a "stocking and glove" type distribution to be obvious. Thus, while such experimental models do not mimic the human disease exactly, particularly in terms of longevity and development of the more chronic clinical complications, they are useful for a detailed study of the initial metabolic and vascular insults that can trigger neuropathy.

\section{Vascular changes and neuropathy in animal models}

Experiments in animal models, particularly the streptozotocin-induced diabetic rat, have shown that reduced sciatic nerve blood flow occurs very early after diabetes induction [33-35]. The same is true for other important peripheral neural structures such as dorsal root and autonomic ganglia ([92], Cameron and Cotter, unpublished observations). The perfusion deficit is sufficient to cause endoneurial hypoxia [33, 93] and therefore closely parallels the sural nerve endoneurial changes noted for neuropathic patients [36-38]. These early events occur well before the development of clear pathological alterations to nerve capillaries, such as basement membrane thickening, and are accompanied by functional deficits such as reduced NCV and increased resistance to ischaemic conduction failure [94].

In addition to the pathological and morphological evidence of vasa nervorum microangiopathy described in longer-term diabetes for human nerves, diabetes also causes several important basic defects in vascular function. These have been found in non-neural tissue in humans and in many vessels and vascular beds, including vasa nervorum, in animal models. Vascular endothelium seems to be particularly vul- 


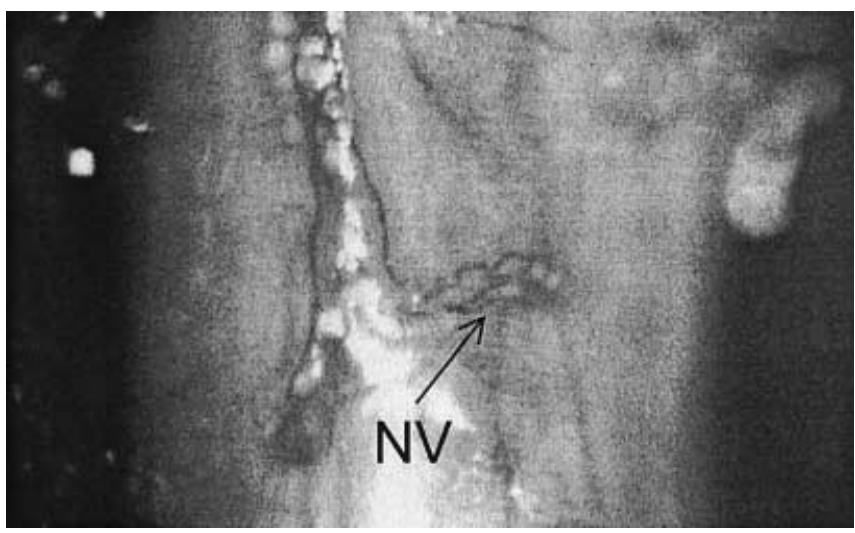

Fig.4. A sural nerve photograph from a subject with "insulin neuritis", showing a fine network of blood vessels resembling the new vessels (NV) of the retina. Reproduced with permission [79]

nerable; deficits have been identified in endotheliumderived vasodilation in patients and animal models [95-98]. Experiments on diabetic rats and rabbits have shown an early impairment of vasorelaxation by the nitric oxide (NO), prostacyclin and endothelium-derived hyperpolarising factor (EDHF) systems [97-103]. Furthermore, there is increased activity in multiple vasoconstrictor mechanisms and in some vessels the production of prostanoid endothelium-derived constricting factors is increased by diabetes [97]. Local vascular production of angiotensin II is increased and circulating ACE concentrations could be increased [104-106]. Diabetes stimulates endothelial endothelin-1 production in rats and circulating endothelin-1 concentrations could be higher in diabetic patients, particularly in those with other evidence of microvascular disease $[107,108]$. Increased endothelin-1 release from other tissues whose expression is increased by diabetes, for example the adrenal glands, could also contribute in principle [109].

Taken together, the data strongly suggests that diabetes alters the balance of vasodilation and vasoconstriction in favour of the latter. Coupled with an increased procoagulatory state, increased blood viscosity, and enhanced adhesion [68-70,110], these deleterious effects on vascular function could be expected to reduce nerve tissue perfusion.

Vasodilator studies. In addition to the studies in humans showing the benefits of vasodilator treatment in DSP [23-25], evidence for the importance of vascular factors in diabetic neuropathy comes from numerous vasodilator studies in experimental diabetes, which show prevention or correction of a wide spectrum of functional changes. A long list of vasodilator agents increase $\mathrm{NCV}$, accompanied by improved nerve blood flow. These agents include ACE inhibitors and antagonists of angiotensin $\mathrm{AT}_{1}$ receptors, endothelin-1 $\mathrm{ET}_{\mathrm{A}}$ receptors, $\alpha_{1}$-adrenoceptors, $\mathrm{Ca}^{2+}$ channels, and serotonin $5 \mathrm{HT}_{2}$ receptors $[49,93,111-117]$. The same is true for several agonists, including $\beta_{2}$-adrenoceptor agonists, prostacyclin, prostaglandin (PG) $\mathrm{E}_{1}$ and $\mathrm{PGE}_{2}$ analogues, nitrodilators, $\mathrm{K}_{\mathrm{ATP}}$ channel openers and a variety of other compounds such as phosphodiesterase inhibitors [114, 118-122]. Several vasodilator studies have also shown the beneficial effects on endoneurial hypoxia, resistance to ischaemic conduction failure, regeneration of damaged nerve fibres and neuropathic pain $[49,93,111,123,124]$. While some of these vasodilators could target the mechanisms underlying diabetes-induced vasa nervorum dysfunction, particularly changes in the angiotensin II and endothelin-1 systems, most simply compensate for the adverse vascular changes and improve nerve blood flow and oxygenation. Thus, explaining how metabolic abnormalities in diabetes cause vascular defects sufficient to compromise nerve integrity, and ascertaining whether there are important parallel exacerbating metabolic insults that impinge directly on nerve fibres is a major challenge.

\section{Metabolic factors and vascular changes in diabetes}

For experimental and theoretical reasons, a variety of metabolic mechanisms dependent on hyperglycaemia and hypoinsulinaemia have been thought to contribute to the aetiology of diabetic complications, including neuropathy. To date, the greatest attention has focussed on advanced glycation, the polyol pathway, oxidative stress, protein kinase $\mathrm{C}$ (PKC) and impaired essential fatty acid metabolism. In nerves, the initial focus has been on direct neuronal effects including glycation of structural proteins, accumulation of sorbitol, myo-inositol depletion and decreased PKC activity, oxidative damage to neuronal membranes and changes in their fatty acid composition $[89,90,94,125]$. Some of these actions were thought to impinge on nerve function via reduced $\mathrm{Na}^{+}, \mathrm{K}^{+}$ATPase activity [125]. However, more recently, studies in animal models and to a limited extent in humans, showed that all of these mechanisms have vascular targets relevant to neuropathy [94]. The potential importance of this is shown in Figure 5, where the results of a substantial number of pharmacological investigations in the streptozotocin-induced diabetic rat model [reviewed in 91] have been plotted to show the relation between sciatic motor NCV and nutritive (capillary) endoneurial blood flow. The data are subdivided into different treatment categories: vasodilators, antioxidants, aldose reductase inhibitors, and other diverse treatments (including PKC inhibitors, essential fatty acids, aminoguanidine, myoinositol and drug combinations). The best fitting non-linear regression curves for these individual categories are very similar; as blood flow increases so does NCV up to an asymptote, that is, within the nor- 


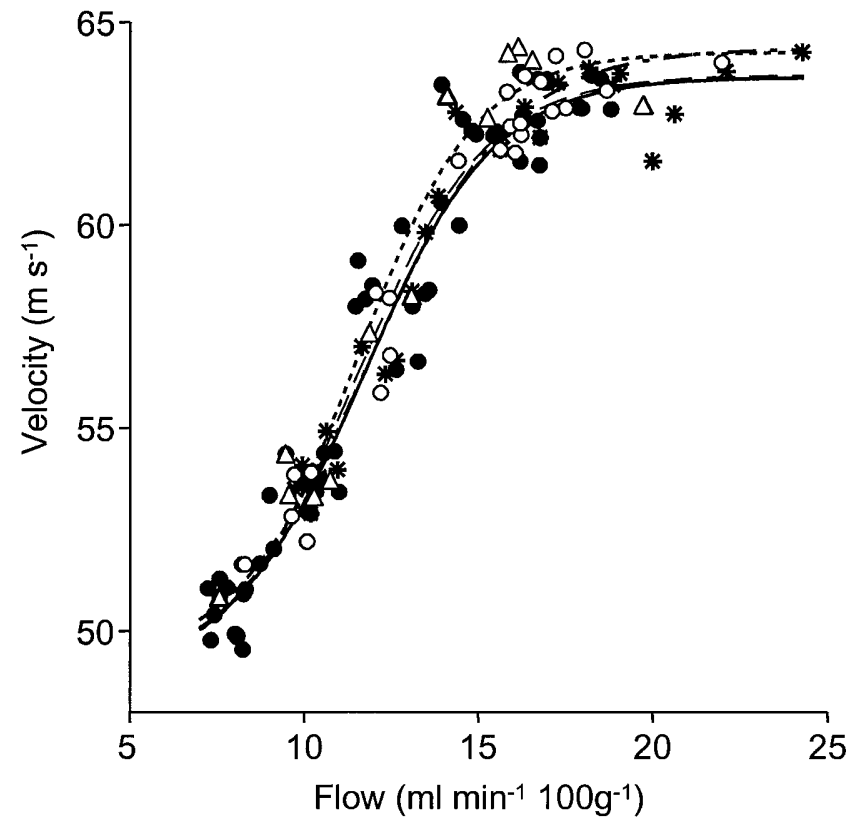

Fig.5. Relation between sciatic motor nerve conduction velocity and endoneurial blood flow in groups of diabetic rats $(n=6-12)$ treated with various drugs in our laboratory. Diabetes duration was 4-12 weeks and treatment was preventive or corrective. The drug treatments are divided into antioxidants $(\bigcirc)$, aldose reductase inhibitors $(\Delta)$, vasodilators $(*)$ or a miscellaneous group $(O)$ comprising aminoguanidine, essential fatty acids, carnitine derivatives, protein kinase $\mathrm{C}$ inhibitors, myo-inositol, a sorbitol dehydrogenase inhibitor, C-peptide, statins and drug mixtures, for example lipoic acid - gamma linolenic acid. The lines are the best-fitting Boltzman curves for each treatment category. All the curves are very similar and well fitted to the data: conduction velocity is low at low flow rates and reaches an asymptote at high flows, corresponding to the non-diabetic range. This emphasises the importance of blood flow changes to nerve conduction

mal range. For the drugs targeting metabolic changes, there is no indication of a substantial divergence from the vasodilator curve, which would be expected if there were important non-vascular or neural components of drug action. Thus, at least as far as animal studies and a simple measure of nerve dysfunction are concerned, the evidence for a predominantly vascular action of these "metabolic" drugs is extremely robust. Questions remain on precisely how such metabolic factors affect nerve blood supply.

Oxidative stress and advanced glycation. Diabetes increases the formation of reactive oxygen species (ROS). Sources of ROS include auto-oxidation of glucose and its metabolites, the advanced glycation process, lipid oxidation, altered prostanoid production, inefficient mitochondrial function, the NADPH oxidase system, inflammatory processes and a variety of other metabolic pathways. ROS could also be produced by the oxidative stress-linked blood flow abnormalities during ischaemia-reperfusion episodes, with a contribution from the xanthine oxidase system.
Oxidative stress could be exacerbated by impaired endogenous antioxidant protection mechanisms, which is particularly relevant for peripheral nerve, although tissue responses to diabetes and oxidative stress vary, some showing up-regulation of protection mechanisms [126-130]. In addition, ROS have a nonpathological role in signal transduction and cell regulation of gene expression, which could also be relevant for diabetes. For example, intracellular ROS are involved in the activation of nuclear factor-kappa $\mathrm{B}$, which participates in the control of endothelial NOS expression [131].

ROS affect the vascular endothelium, damaging cells and altering specific functions. Nitric oxide is an important target for ROS. Superoxide from a variety of sources can react with NO produced by vascular endothelium or nitrergic nerves, to form peroxynitrite $\left(\mathrm{ONO}_{2}^{-}\right)$, which would reduce endothelium-dependent relation and nitrergic neurotransmission. The peroxynitrite nitrosylates proteins, potentially altering their function and increased concentrations of nitrotyrosine have been noted in vessels from diabetic patients and endothelial cells cultured under high glucose conditions $[132,133]$. Peroxynitrite also breaks down to give highly reactive hydroxyl radicals that are cytotoxic [134]. Chronic treatment with the ROS scavengers vitamin E, butylated hydroxytoluene, acetylcysteine, $\alpha$-lipoic acid, or the hydroxyl radical scavenger, dimethylthiourea, protect the vascular NO system in diabetic rats [97, 135-137] and there are some indications of similar effects in diabetic patients [138]. A preliminary report also suggests that antioxidants ameliorate diabetic EDHF defects [139].

Oxidative stress is also involved in the increase in vascular angiotensin II activity, and antioxidants reduce plasma ACE concentrations in diabetic rats [105]. Scavengers, such as those listed above, improve $\mathrm{NCV}$ and blood flow in experimental diabetes, actions that are markedly attenuated by NO synthase inhibitor cotreatment [105, 129, 140-142]. Moreover, beneficial scavenger effects have been noted for endoneurial oxygen tension, nerve morphometry, regeneration of damaged nerve fibres and corpus cavernosum innervation [105, 143-145].

The peroxynitrite mechanism can be enhanced in diabetes not only by increased superoxide formation but also by up-regulation of NOS in some tissues, particularly early on in the disease [131]. Endotheliumdependent relaxation of aorta from diabetic rats could be protected by NO scavenger treatment [146]. The early degenerative changes of corpus cavernosum nitrergic innervation were partially attenuated by NO synthase inhibitor treatment [147]. However, this approach would not be generally suitable for treatment of nerve and vasa nervorum dysfunction. Thus, there is no evidence of NOS up-regulation in vas nervorum [89]. Chronic NOS inhibition causes 
neuropathic damage by reducing nerve blood flow in non-diabetic rats and it opposes the beneficial effects of various vasoactive agents in diabetic rats including vasodilators, aldose reductase inhibitors, protein kinase $\mathrm{C}$ inhibitors, antioxidants and aminoguanidine on nerve function [50, 148-150]. Thus, for peripheral neuropathy, increasing vasodilation to restore vasa nervorum perfusion is a primary concern, even when nitrodilators are used to further increase NO [120]. The practical vascular benefits of antioxidant therapy in inhibiting the formation of ROS and peroxynitrite clearly outweigh those of a theoretical remedy based on agents that reduce NO availability, which would also exacerbate hypertension, a risk factor for neuropathy[14].

In general, both lipophilic and hydrophilic scavengers are effective against endothelial and nerve dysfunction in experimental diabetes. However, extremely large doses are often required, for example, $1 \mathrm{~g} \cdot \mathrm{kg}^{-1} \mathrm{day}^{-1}$ of vitamin E $[135,141,144]$. Not only does this limit potential therapeutic application but it also suggests that scavenging might not be a particularly effective approach. It is necessary to increase our detailed understanding of the importance of potential sources of ROS in diabetes, their localisation and the processes involved in their formation.

LDL is oxidised in diabetes, the lipid content undergoing peroxidation chain reactions [126]. This source of hydroxyl radicals can cause endothelial damage [151]. A lipid-lowering strategy would reduce this cause of oxidative stress, which could be important as higher lipids are a risk factor for neuropathy and endothelial dysfunction [14, 152]. Endothelium-dependent relaxation in diabetic mice was protected by treatment with the lipid-lowering drug, cholestyramine [153]. A similar strategy has recently been applied to vasa nervorum; NCV and blood flow deficits were corrected by statin treatment of diabetic rats [154].

Another approach is to prevent ROS formation by auto-oxidation and the Fenton reaction, which are catalysed by free transition metal ions, particularly iron and copper. The normally tight regulation of free transition metals is compromised by diabetes $[155$, 156]. Low doses of the transition metal chelators, deferoxamine and trientine, completely corrected sciatic nerve perfusion and NCV deficits in diabetic rats [157]. Chronic chelator treatment prevented defective aorta and corpus cavernosum endothelium-dependent relaxation, and attenuated defects in cavernosal nitrergic nerve function [97, 158]. Interestingly, a single intravascular injection of a macromolecular dextran conjugate of deferoxamine caused longlasting improvements in nerve blood flow and NCV in diabetic rats, so that it took one month for values to return to the diabetic level [159]. Moreover, the initial increase in NCV lagged behind that of perfusion, which suggests that vascular changes, rather than a direct ROS action on nerve fibres, cause the NCV defect. Thus, transition metal dysregulation appears to make an important contribution to ROS generation in experimental diabetes, with a gradual build-up of free iron and copper in blood or vascular tissue which could be controlled by periodic chelator treatment. In diabetic patients, clinical neuropathy trials are underway using lipoic acid, which is both a scavenger and metal chelator. Early reports show some benefits for symptomatic and autonomic neuropathy as well as modest improvements in NCV [160].

The non-enzymatic reaction of reducing sugars with protein amino groups and lipids gives rise to the formation of reactive dicarbonyl intermediates by auto-oxidation, which then further react to form a variety of advanced glycation end products (AGEs) $[126,127,161]$. It is difficult to separate the effects of oxidative stress from changes due to AGE production because the latter produces ROS and is accelerated by ROS. Moreover, transition metal-catalysed auto-oxidation is involved in AGE formation and AGEs bind transition metals in such a way that they remain redox active [127, 162]. AGEs have marked vascular effects, both directly and by binding to specific receptors [161]. The latter could mediate signal transduction through ROS generation to activate nuclear transcription factor $\varkappa \mathrm{B}$, which is involved in cell injury responses. Antioxidants inhibit AGE formation and the effects of AGE receptor activation [126]. AGEs can affect the endothelial NO system by ROS generation and also by directly quenching NO $[133,161]$. Chronic treatment with aminoguanidine, which reacts with dicarbonyl intermediates to inhibit AGE formation, prevented the development of aorta NO-mediated endothelium-dependent relaxation deficits in diabetic rats [137]. Aminoguanidine treatment also prevents and corrects nerve blood flow and NCV deficits and prevents deficits in neuronal morphology in diabetic rats $[89,128,148]$. However, aminoguanidine is not only an AGE inhibitor but also blocks the inducible isoform of NO synthase. This does not contribute to the beneficial neurovascular actions of aminoguanidine, which are abolished by cotreatment with a non-specific NO synthase inhibitor [148]. Aminoguanidine also inhibits semicarbazide-sensitive amine oxidase, which is located in several tissues including arterial vessel walls. This enzyme is higher in diabetes and can catalyse the breakdown of aminoacetone to methylglyoxal and the ROS, hydrogen peroxide [163]. The former is a reactive carbonyl species involved in AGE formation [126] and the latter would further contribute to oxidative stress.

Thus, it is clear that the increased generation of ROS and AGEs in diabetes have marked neurovascular actions, sufficient to account for many, if not all, of the nerve function changes in experimental diabetes. However, in the long-term, direct ROS effects 
on neurones could contribute to degeneration, for example by impaired mitochondrial function which could be linked to the apoptosis-like changes seen in neuronal ganglionic cell bodies [87, 92]. These events could also be triggered by reduced peripheral ganglion and nerve blood flow [92].

Polyol pathway. Increases in polyol pathway activity have long been thought to be an important in diabetic complications, particularly for neuropathy and there have been several major clinical trials of aldose reductase inhibitors (ARIs), which block the first enzyme in the pathway. Several of the ARI trials, which have been reviewed in detail, showed relatively modest improvements in nerve function and morphometry [164-166]. In marked contrast, studies in animal models show far more profound actions [89, 90, 94, 125, 164, 165]. Reasons for this discrepancy have been debated [94, 165] but could in part be because a crucial issue is the ARI dose necessary for neurochemical effects on sorbitol accumulation in nerves compared to the dose necessary for functional changes. Thus, in diabetic rats, a $90 \%$ correction of a motor NCV deficit can require a greater than 30 -fold higher dose than for $90 \%$ inhibition of nerve sorbitol [167]. Trials on the effectiveness of ARI's biochemical efficacy in lowering nerve polyols will, perforce, have a similar discrepancy for functional measures such as NCV. ARIs have profound effects on nerve blood flow and it is this that correlates with NCV (Fig. 5). Moreover, ARI dose-response studies show that blood flow effects closely parallel those on NCV [167]. The actions of ARIs on vascular endothelium are very similar to those of antioxidants, protecting the NO and EDHF systems [100]. This could be because ARI treatment improves the concentration of the endogenous antioxidant, glutathione, which is reduced in nerve and vascular tissue $[121,168]$. Certain ARIs of the spirohydantoin type, such as sorbinil, have also been shown to have transition metal chelation properties at high doses in vitro, which could potentially contribute to their antioxidant-like action if it occurs in vivo [169]. However, this putative mechanism is not likely to be important for the more recently developed and highly potent third generation ARIs, or for carboxylic acid and suphonylnitromethane derived ARIs [164, 167]. As with antioxidants, ARI effects on nerve perfusion and NCV are blocked by NO synthase inhibition, while their polyol lowering action does not change [149].

The first step of the polyol pathway, catalysed by aldose reductase, seems more important for neurovascular actions than the second sorbitol dehydrogenase-dependent step. Thus, inhibitors of sorbitol dehydrogenase, while being biochemically effective, do not alter nerve blood flow or NCV in the shortterm [170]. In fact, they might exacerbate oxidative stress by further depressing tissue glutathione con- centration [168], which in the long-term could be responsible for the increase in dystrophic changes of mesenteric nerves seen with these agents [171]. Thus, the first polyol pathway step appears to be an important contributor to oxidative stress in experimental diabetes and actions on vasa nervorum are primarily responsible for its role in early nerve dysfunction.

Protein kinase C. Another mechanism, increased PKC activation, has been implicated in diabetic complications and could in part act to mediate oxidative stress-related neurovascular effects. PKC is activated by hyperglycaemia-driven de novo synthesis of diacylglycerol and also by oxidative stress [172]. In vessels and vascular tissue, $\mathrm{PKC}$, particularly the $\beta$ isoform, is higher. In nerves, this is not usually observed $[150,173]$, indeed reductions have been claimed to be central to the pathogenesis of diabetic neuropathy by modulating $\mathrm{Na}^{+}, \mathrm{K}^{+}$ATPase activity [125]. Despite the prediction from the neurochemical hypothesis that PKC inhibitor treatment would further exacerbate nerve dysfunction, several PKC inhibitors and diacylglycerol complexing agents were found in fact to improve NCV in diabetic rats $[150,173,174]$, although the improvement was not sustained for non-specific agents at very high doses [150]. The beneficial effects on NCV were mediated by vasa nervorum and improved nerve blood flow [150, 173, 174]. As with antioxidants and ARIs, the neural action of PKC inhibitors in diabetic rats was blocked by cotreatment with a NO synthase inhibitor $[150$, 174]. Moreover, chronic treatment with the $\mathrm{PKC} \beta$ inhibitor, LY333531, attenuated deficits in endothelium-dependent relaxation mediated by the NO and EDHF systems in diabetic rats [175].

Essential fatty acids and interactions with oxidative stress. The metabolism of $\omega-6$ essential fatty acids is impaired by diabetes, the $\Delta-6$ and $\Delta-5$ desaturation steps in the conversion of linoleic acid to arachidonic acid being particularly compromised [176]. This limits the production of 1 and 2 series prostanoids and lipoxygenase products. Vasa nervorum production of the vasodilator and inhibitor of platelet aggregation, prostacyclin $\left(\mathrm{PGI}_{2}\right)$, is reduced in diabetic rats [103]. The rate limiting $\Delta-6$ desaturation deficit can be bypassed by treatment with oils containing $\gamma$-linolenic acid or arachidonic acid, resulting in increased nerve blood flow and NCV and attenuation of the development of resistance to ischaemic conduction failure $[176,177]$. These functional effects were reduced by cotreatment with cyclooxygenase inhibitors [149, 176]. Thus, the beneficial effects of $\omega-6$ essential fatty acid treatment has been suggested to be due to the restoration of vasa nervorum $\mathrm{PGI}_{2}$ production by improving substrate availability [176]. Recently, treatment with evening primrose oil, which is rich in $\gamma$-li- 
nolenic acid, was also found to improve the EDHF system in mesenteric vessels of diabetic rats and to boost it in non-diabetic animals [178]. The reason for this is not clear, primarily because the chemical identity of EDHF has not been established. However, one suggestion is that EDHF is an epoxyeicosatrienoic acid product of arachidonic acid metabolism by cytochrome P450 [179]. If this proves to be the case, then $\omega-6$ essential fatty acid treatment could be providing substrate for EDHF as well as $\mathrm{PGI}_{2}$ synthesis. Clinical trials of evening primrose oil show NCV and sensory threshold improvements as well as a slowing of neuropathy progression [176].

Polyunsaturated fatty acids, including the $\omega-6$ and $\omega-3$ essential fatty acids, are a major target for ROS damage. Indeed, without antioxidant protection they can be the sites of destructive lipid peroxidation chain reactions. Thus, they can be viewed as potential prooxidants and vehicles for ROS carriage, for example to vascular endothelium. This is balanced by their positive actions to promote endothelium-derived vasodilation by $\mathrm{PGI}_{2}$ and EDHF. Essential fatty acids are also necessary for the normal structure and function of cell membranes and influence membrane fluidity and the microenvironment and activity of membrane-bound proteins [176]. As antioxidants can protect essential fatty acids from ROS and also promote endothelium dependent relaxation, albeit with a somewhat different spectrum of action with greater emphasis on $\mathrm{NO}$, the effects of joint antioxidant and $\gamma$-linolenic acid therapies have been examined. These proved to have synergistic actions on both nerve blood flow and NCV in diabetic rats [142, 180]. The most striking neurovascular effect was seen with an equimolar lipoic acid / $\gamma$-linolenic acid combination where there was a synergy equivalent to a fivefold amplification of drug action. The effect was specific, as substituting the $\omega-3$ components, docosahexaenoic acid or eicosapentaenoic for $\gamma$-linolenic acid abolished the synergistic effects [142]. In these and other examples of synergistic drug interactions studied, the correction of blood flow occurred in parallel to function improvements, emphasising a causal link [113, $142,149,180]$.

\section{Conclusions}

It is clear that impaired blood flow and endoneurial hypoxia play a major role in causing diabetic neuropathy in human and animal models. There is a complex series of metabolic changes that interact to cause reduced nerve perfusion (Fig.6). Animal studies suggest that major defects arise from hyperglycaemia and altered lipid handling, a hypothesis in accord with epidemiological data on humans. Oxidative stress-related mechanisms play a central role in vascular dysfunction, altering the balance between va-

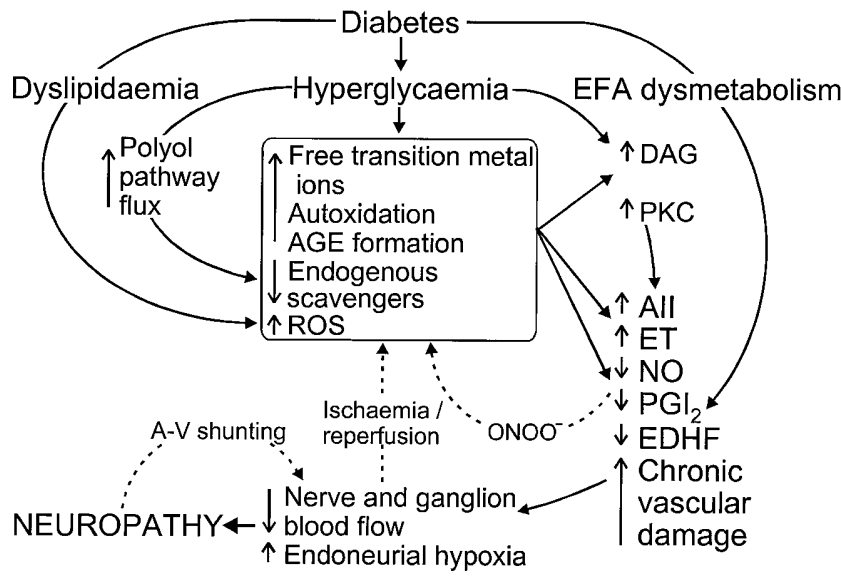

Fig. 6. Schematic of the metabolic and vascular interactions that alter neurovascular function in diabetes. AII, angiotensin 2; AGE, advanced glycation end product; A-V, arterio-venous; DAG, diacylglycerol; EDHF, endothelium-derived hyperpolarising factor; EFA, essential fatty acid; ET, endothelin-1; NO, nitric oxide; $\mathrm{ONOO}^{-}$, peroxynitrite; $\mathrm{PGI}_{2}$, prostacyclin; $\mathrm{PKC}$, protein kinase $\mathrm{C}$; ROS, reactive oxygen species

sodilation and vasoconstriction in favour of the latter. These early changes in vascular function give way to progressive chronic endoneurial vascular damage that accompanies the neurodegeneration seen in biopsy samples from patients. The link between vascular dysfunction and long-term degenerative changes is not entirely clear and merits future attention. Alterations in flow patterns appear to be very important, particularly the increase in arterio-venous shunting in vasa nervorum, which could in part be a product of the neuropathic process involving autonomic fibres. Questions remain on the nature of the earliest nerve blood flow changes in humans and their relation to neuropathy, and also on the details of the role of vascular factors in neuropathic pain. The few clinical trials using drugs targeting the vascular changes in diabetes have shown that it is possible to slow or halt the progression of neuropathy or even give rise to improvements in nerve function. Animal studies have identified many other metabolic-vascular drug targets that have yet to be examined in human beings, and the hope is that at least one of these approaches will prove to have substantial therapeutic benefits.

Sources. The review is based on the relevant literature published in the English language during the period 1990-2001 and seminal prior contributions. The sources available to the authors were integrated with sources identified through PubMed, Medline and Web of Science searches using keyword combinations of diabetes, neuropathy, endothelium, blood flow, ischaemia, nerve conduction, sensory testing, pain and vasa nervorum. 


\section{References}

1. Diabetes Control and Complications Trial Group (1995) Effect of intensive diabetes treatment on nerve conduction in the Diabetes Control and Complications Trial. Ann Neurol 38: 869-880

2. United Kingdom Prospective Diabetes Study Group (1998) Intensive blood glucose control with sulphonylureas or insulin compared with conventional treatment and risk of complication in patients with type 2 diabetes (UKPDS 33). Lancet 352: 837-853

3. Ward JD (1999) Improving the prognosis in type 2 diabetes: diabetic neuropathy is in trouble. Diabetes Care 22: B84-B88

4. Vinik A, Park T, Stansberry K, Pittenger G (2000) Diabetic Neuropathies. Diabetologia 43: 957-973

5. Eaton SEM, Tesfaye S (1999) Clinical manifestations and measurement of somatic neuropathy. Diabetes Rev 7: 312-325

6. Watkins PJ, Edmonds ME (1997) Clinical features of diabetic neuropathy. In: Pickup J, Williams G (eds) Textbook of Diabetes, 2nd edn. Blackwell, Oxford, pp 50.1-50.20

7. Watkins PJ (1984) Pain and diabetic neuropathy. BMJ 228: $168-169$

8. Tesfaye S, Watt J, Benbow SJ, Pang KA, Miles J, MacFarlane IA (1996) Electrical spinal cord stimulation for painful diabetic peripheral neuropathy. Lancet 348: 1696-1701

9. Andersen H, Jakobsen J (1999) Motor function in diabetes. Diabetes Rev 7: 326-341

10. Thomas PK, Lascelles RG (1965) Schwann-cell abnormalities in diabetic neuropathy. Lancet i: 1355-1356

11. Dyck PJ, Karnes JL, O'Brien PC, Okazaki H, Lias A, Engelstad J (1986) The spatial distribution of fibre loss in diabetic polyneuropathy suggests ischaemia. Ann Neurol 19: 425-439

12. Boulton AJM (1997). Foot problems in patients with diabetes mellitus. In: Pickup J, Williams G (eds) Textbook of Diabetes. 2nd edn. Blackwell, Oxford, pp 58.1-58.20

13. Shaw J, Zimmet P (1999) The epidemiology of diabetic neuropathy. Diabetes Rev 7: 245-252

14. Tesfaye S, Stevens L, Stephenson J et al. (1996) The prevalence of diabetic peripheral neuropathy and it's relation to glycaemic control and potential risk factors: The EURODIAB IDDM complications study. Diabetologia 39: 1377-1384

15. Fedele D, Comi G, Coscelli C et al. (1997) A multicentre study on the prevalence of diabetic neuropathy in Italy: Italian Diabetic Neuropathy Group. Diabetes Care 20: 836-843

16. Jude E, Boulton AJM (1999) End stage complications of diabetic neuropathy. Diabetes Rev 7: 395-410

17. Johnson FN, Williams R (1997) Economic aspects of diabetic neuropathy and related diabetic complications. In: Boulton AJM (ed) Diabetic Neuropathy.1st edn. Marius Press, Carnforth, pp 77-95

18. Holzer S, Camerota A, Martens L, Cuerdon T, Crystal-Peters J, Zagari M (1998) Costs and duration of care for lower extremity ulcers in patients with diabetes. Clin Ther 20: 169-181

19. Jaap A, Hammersley M, Shore A, Tooke JE (1994) Reduced microvascular hyperaemia in subjects at risk of developing type 2 (non-insulin dependent) diabetes mellitus. Diabetologia 37: 214-216

20. Caballero AE, Arora S, Saouaf R et al. (1999) Microvascular and macrovascular reactivity is reduced in subjects at risk for type 2 diabetes. Diabetes 48: 1856-1862
21. Forrest K, Maser R, Pambianco G, Becker D, Orchard T (1997) Hypertension as a risk factor for diabetic neuropathy: a prospective study. Diabetes 46: 665-670

22. Tesfaye S, Chaturvedi N, Eaton SEM, Ward JD, Fuller J, and the EURODIAB Study Group (2000) Cardiovascular risk factors predict development of diabetic peripheral neuropathy. Diabetes 49 [Supp 1]: A34 (Abstract)

23. Reja A, Tesfaye S, Harris ND, Ward JD (1995) Is ACE inhibition with lisinopril helpful in diabetic neuropathy? Diabetic Med 12: 307-309

24. Malik R, Williamson S, Abbott CA et al. (1998) Effect of the angiotensin converting enzyme inhibitor trandalopril on human diabetic neuropathy: a randomised controlled trial. Lancet 352: 1978-1981

25. Hotta N, Nakamura J, Sumita Yet al. (1999) Effects of the $5-\mathrm{HT}_{2 \mathrm{~A}}$ receptor antagonist sarpogrelate in diabetic patients with complications - A pilot study. Clin Drug Invest 18: 199-207

26. Maser R, Steenkiste A, Dorman J et al. (1989) Epidemiological correlates of diabetic neuropathy. Report from the Pittsburgh Epidemiology of Diabetic Complications Study. Diabetes 38: 1456-1461

27. Gaede P, Vedel P, Parving H, Pederson O (1999) Intensified multifactorial intervention in patients with type 2 diabetes mellitus and microalbuminuria: the Steno type 2 randomised study. Lancet 353: 617-622

28. Kohner E, Patel V, Rassam S (1995) Role of blood flow and impaired autoregulation in the pathogenesis of diabetic retinopathy. Diabetes 44: 603-607

29. Bursell SE, Clermont AC, Aiello LP et al. (1999) Highdose vitamin $\mathrm{E}$ supplementation normalizes retinal blood flow and creatinine clearance in patients with type 1 diabetes. Diabetes Care 22: 1245-1251

30. Patz A (1982) Clinical and experimental studies on retinal neovascularisation. Am J Ophthalmol 94: 715-743

31. Aiello L, Avery R, Arrigg P (1994) Vascular endothelial growth factor in ocular fluid of patients with diabetic retinopathy and other retinal disorders. N Engl J Med 331: 1480-1487

32. Mogensen C (1994) Glomerular hyperfiltration in human diabetes. Diabetes Care 17: 770-775

33. Tuck R, Schmelzer J, Low PA (1984) Endoneurial blood flow and oxygen tension in the sciatic nerves of rats with experimental diabetic neuropathy. Brain 107: 935-950

34. Cameron NE, Cotter MA, Low PA (1991) Nerve blood flow in early experimental diabetes in rats: relation to conduction defects. Am J Physiol 261: E1-E8

35. Wright RA, Nukuda H (1994) Vascular and metabolic factors in the pathogenesis of experimental diabetic neuropathy in mature rats. Brain117: 1395-1407

36. Newrick PG, Wilson AJ, Jakubowski J, Boulton AJM, Ward JD (1986) Sural nerve oxygen tension in diabetes. BMJ 293: 1053-1054

37. Ibrahim S, Harris N, Radatz M et al. (1999) A new minimally invasive technique to show nerve ischaemia in diabetic neuropathy. Diabetologia 42: 737-742

38. Tesfaye S, Harris ND, Jakubowski J et al. (1993) Impaired blood flow and arterio-venous shunting in human diabetic neuropathy: a novel technique of nerve photography and fluoroscein angiography. Diabetologia 36: 1266-1274

39. Theriault M, Dort J, Sutherland G, Zochodne DW (1997) Local human sural nerve blood flow in diabetic and other polyneuropathies. Brain 120: 1131-1138

40. Jorneskog G, Brismar K, Fagrell B (1995) Skin capillary circulation severely impaired in toes of patients with IDDM, with and without late diabetic complications. Diabetologia 38: 474-480 
41. Young MJ, Veves A, Walker MG, Boulton AJM (1992) Correlation between nerve function and tissue oxygenation in diabetic patients: further clues to the aetiology of diabetic neuropathy? Diabetologia 35: 1146-1150

42. Ram Z, Sadeh M, Walden R, Adar R (1991) Vascular insufficiency quantitatively aggrevates diabetic neuropathy. Arch Neurol 48: 1239-1242

43. Young MJ, Veves A, Smith JV, Walker MG, Boulton AJM (1995) Restoring limb blood flow improves nerve function in diabetic patients. Diabetologia 38: 1051-1054

44. Tesfaye S, Harris ND, Wilson RM, Ward JD (1992) Exercise induced conduction velocity increment: a marker of impaired peripheral nerve blood flow in diabetic neuropathy. Diabetologia 35: 155-159

45. Malik R, Masson EA, Sharma AK et al. (1990) Hypoxic neuropathy: relevance to human diabetic neuropathy. Diabetologia 33: 311-318

46. Newrick PG, Boulton AJM, Ward JD (1987) Nerve ischaemia resistance: an early change in diabetes mellitus. Diabetic Med 4: 517-520

47. Masson EA, Church S, Woodcock A, Hanley S, Boulton AJM (1988) Is resistance to ischaemic conduction failure induced by hypoxia? Diabetologia 31: 762-765

48. Parry GJ, Kohzu H (1989) Studies of resistance to ischemic nerve conduction failure in normal and diabetic rats. J Neurol Sci 93: 61-67

49. Cameron NE, Cotter MA, Ferguson K, Robertson S, Radcliffe MA (1991) Effects of chronic á-adrenergic receptor blockade on peripheral nerve conduction, hypoxic resistance, polyols, Na-K ATPase activity and vascular supply in streptozocin-diabetic rats. Diabetes 40: 1652-1658

50. Cameron NE, Cotter MA, Dines KC, Maxfield EK (1993) Pharmacological manipulation of vascular endothelium in non-diabetic and streptozotocin-diabetic rats: effects on nerve conduction, hypoxic resistance and endoneurial capillarization. Diabetologia 36: 516-522

51. Pryce T (1893) On diabetic neuritis with a clinical and pathological description of three cases of diabetic pseudo-tabes. Brain 16: 416-424

52. Fagerberg S (1959) Diabetic neuropathy: a clinical and histological study on the significance of vascular affections. Acta Med Scand 164: 5-81

53. Bischoff A (1980) Morphology of diabetic neuropathy. Horm Metab Res 9: 18-28

54. Powell H, Rosoff J, Myers R (1985) Microangiopathy in human diabetic neuropathy. Acta Neuropathol (Berl) 68: 295-305

55. Giannini C, Dyck PJ (1995) Basement membrane thickening and pericyte degeneration precede development of diabetic polyneuropathy and are associated with its severity. Ann Neurol 37: 498-504

56. Malik R, Veves A, Masson EA et al. (1992) Endoneurial capillary abnormalities in mild human diabetic neuropathy. J Neurol Neurosurg Psychiatry 55: 557-561

57. Malik R, Newrick PG, Sharma AK et al. (1989) Microangiopathy in human diabetic neuropathy; relationship between capillary abnormalities and the severity of neuropathy. Diabetologia 32: 92-10258

58. Britland ST, Young RJ, Sharma AK, Clarke BF (1990) Relationship of endoneurial capillary abnormalities to type and severity of diabetic neuropathy. Diabetes 39: 909-913

59. Giannini C, Dyck PJ (1999) Pathologic alterations in human diabetic polyneuropathy. In: Dyck PJ, Thomas PK (eds) Diabetic Neuropathy. 2nd edn. Saunders, Philadelphia, pp 279-295
60. Yasuda H, Dyck PJ (1987) Abnormalities of endoneurial microvessels and sural nerve pathology in diabetic neuropathy. Neurology 37: 20-28

61. Malik R, Tesfaye S, Thompson SD et al (1993) Endoneurial localisation of microvascular damage in human diabetic neuropathy. Diabetologia 36: 454-459

62. Llewelyn JG, Thomas PK, Gilbey SG, Watkins PJ, Muddle JR (1988) Pattern of myelinated fibre loss in sural nerve in neuropathy related to type 1 insulin-dependent diabetes. Diabetologia 31: 162-167

63. Timperley W, Ward JD, Preston F, Duckworth T, O'Malley B (1976) Clinical and histological studies in diabetic neuropathy. Diabetologia 12: 237-243

64. Williams E, Timperley W, Ward JD, Duckworth T (1980) Electromicroscopical studies of vessels in diabetic neuropathy. J Clin Pathol 33: 462-470

65. Timperley W, Boulton AJM, Davies-Jones GAB, Jarratt JA, Ward JD (1985) Small vessel disease in progressive diabetic neuropathy associated with good metabolic control. J Clin Pathol 38: 1030-1038

66. Dyck PJ, Hansen S, Karnes JL, O'Brien PC, Yasuda H, Windebank AJ (1985) Capillary number and percentage closed in human diabetic sural nerve. Proc Natl Acad Sci USA 82: 2513-2517

67. O'Malley B, Timperley W, Ward J, Porter N, Preston F (1975) Platelet abnormalities in diabetic neuropathy. Lancet ii: $1274-1276$

68. McMillan D, Utterback N, La Puma J (1978) Reduced erythrocye deformability in diabetes. Diabetes 27: 895-901

69. Wautier J-L, Paton R, Wautier M et al. (1981) Increased adhesion of erythrocytes to endothelial cells in diabetes mellitus and its relation to vascular complications. N Engl J Med 305: 237-242

70. Simpson LO (1988) Altered blood rheology in the pathogenesis of diabetic and other neuropathies. Muscle Nerve 11: 725-744

71. Ford I, Malik R, Newrick PG, Preston F, Ward JD, Greaves M (1992) Relationship between haemstatic factors and capillary morphology in human diabetic neuropathy. Thromb Haemost 68: 628-633

72. Malik R (1997) The pathology of human diabetic neuropathy. Diabetes 46 [Supp 2]: S50-S53

73. Beggs J, Johnson P, Olafsen A, Watkins C, Cleary C (1991) Transperineurial arterioles in human sural nerve. J Neuropathol Exp Neurol 50: 704-718

74. Beggs J, Johnson P, Olafsen A, Watkins C (1992) Innervation of the vasa nervorum: changes in human diabetics. J Neuropathol Exp Neurol 51: 612-629

75. Boulton AJM, Scarpello JHB, Ward JD (1982) Venous oxygenation in the diabetic foot: evidence of arteriovenous shunting. Diabetologia 22: 6-8

76. Tesfaye S, Malik R, Harris ND et al. (1996) Arterio-venous shunting and proliferating new vessels in acute painful neuropathy of rapid glycaemic control (insulin neuritis). Diabetologia 39: 329-335

77. Roberts J (1948) The effect of occlusive arterial disease of the extremeties on the blood supply of the nerves: experimental and clinical studies on the vasa nervorum. Am Heart J 35: 369-392

78. Nukada H, Dyck PJ (1984) Microsphere embolization of nerve capillaries and fiber degeneration. Am J Pathology 115: 275-287

79. Johnson P, Doll S, Cromey D (1986) Pathogenesis of diabetic neuropathy. Ann Neurol 19: 450-45780

80. Kihara M, Zollman PJ, Smithson IL, Lagerlund TD, Low PA (1994) Hypoxic effect of exogenous insulin on normal 
and diabetic peripheral nerve. Am J Physiol 266: E980-E985

81. Eaton SEM, Harris ND, Ibrahim S et al. (2000) Sural nerve haemodynamics in painful and painless neuropathy: clues to the cause of pain? Diabetes Res Clin Pract 50 [Supp 1]: S273 (Abstract)

82. Hopf HC, Gutmann L (1990) Diabetic third nerve palsy: evidence for a mesencephalic lesion. Neurology 40: 1041-1045

83. Asbury AK, Aldredge H, Hershberg R, Fisher CM (1970) Oculomotor palsy in diabetes mellitus: a clinicopathological study. Brain 93: 555-557

84. Sunderland S, Hughes ESR (1946) The pupilloconstrictor pathway and the nerves to the ocular muscles in man. Brain 69: 301-309

85. Jakobsen J (1979) Early and preventable changes of peripheral nerve structure and function in insulin-deficient diabetic rats. J Neurol Neurosurg Psychiatry 42: 509-518

86. Cameron NE, Leonard MB, Ross I, Whiting P (1986) The effects of Sorbinil on peripheral nerve conduction velocity, polyol concentrations and morphology in the streptozotocin diabetic rat. Diabetologia 29: 168-174

87. Russell JW, Sullivan KA, Windebank AJ, Herrmann DN, Feldman EL (1999) Neurons undergo apoptosis in animal and cell culture models of diabetes. Neurobiol Disease 6: 347-363

88. Mattingly GE, Fischer VW (1983) Peripheral neuropathy following prolonged exposure to streptozotocin induced diabetes in rats: a teased fiber study. Acta Neuropathol (Berl) 59: 133-138

89. Yagihashi S (1995) Pathology and pathogenetic mechanisms of diabetic neuropathy. Diabetes Metab Rev 11: 193-225

90. Sima AAF, Sugimoto K (1999) Experimental diabetic neuropathy: an update. Diabetologia 42: 773-788

91. Cameron NE, Cotter MA (2000) New therapeutic approaches to prevent or halt the progression of the longterm complications of diabetes mellitus: focus on neuropathy. Curr Opin Oncol Endocrin Metab Investigational Drugs 2: 162-17792

92. Sasaki H, Schmelzer JD, Zollman PJ, Low PA (1997) Neuropathology and blood flow of nerve, spinal roots and dorsal root ganglia in longstanding diabetic rats. Acta Neuropathol (Berl) 93: 118-128

93. Maxfield EK, Love A, Cotter MA, Cameron NE (1995) Nerve function and regeneration in diabetic rats: effects of ZD7155, an $\mathrm{AT}_{1}$ receptor antagonist. Am J Physiol 269: E530-E537

94. Cameron NE, Cotter MA (1994) The relationship of vascular changes to metabolic factors in diabetes mellitus and their role in the development of peripheral nerve complications. Diabetes Metab Rev 10: 189-224

95. Morris SJ, Shore AC, Tooke JE (1995) Responses of the skin microcirculation to acetylcholine and sodium nitroprusside in patients with NIDDM. Diabetologia 38: 1337-1344

96. Arora S, Smakowski P, Frykberg RG et al. (1998) Differences in foot and forearm skin microcirculation in diabetic patients with and without neuropathy. Diabetes Care 21: 1339-1344

97. Pieper GM (1998) Review of alterations in endothelial nitric oxide production in diabetes: protective role of arginine on endothelial dysfunction. Hypertension 31: 1047-1060

98. Kamata K, Miyata N, Kasuya Y (1989) Impairment of endothelium-dependent relaxation and changes in levels of cyclic GMP in aorta from streptozotocin-induced diabetic rats. Br J Pharmacol 97: 614-618
99. FukaoY, Hattori Y, Kanno M, Sakuma I, Kitabatake A (1997) Alterations in endothelium-dependent hyperpolarization and relaxation of mesenteric arteries from streptozotocin-induced diabetic rats. $\mathrm{Br} \mathrm{J}$ Pharmacol 121: 1383-1391

100. Keegan A, Jack AM, Cameron NE, Cotter MA (2000) Effects of aldose reductase inhibition on responses of the corpus cavernosum and mesenteric vascular bed of diabetic rats. J Cardiovasc Pharmacol 35: 606-613

101. Kihara M, Low PA (1995) Impaired vasoreactivity to nitric oxide in experimental diabetic neuropathy. Exp Neurol 132: 180-185

102. Maxfield EK, Cameron NE, Cotter MA (1997) Effect of diabetes on reactivity of sciatic vasa nervorum in rats. J Diabet Complications 11: 47-55

103. Ward KK, Low PA, Schmelzer JD, Zochodne DW (1989) Prostacyclin and noradrenaline in peripheral nerve of chronic experimental diabetes in rats. Brain 112: 197-208

104. Cooper ME, Rumble J, Komers R, He-cheng D, Jandeleit K, Sheung-to C (1994) Diabetes-associated mesenteric vascular hypertrophy is attenuated by angiotensin-converting enzyme inhibition. Diabetes 43: 1221-1228105

105. Cameron NE, Cotter MA, Archibald V, Dines KC, Maxfield EK (1994) Anti-oxidant and pro-oxidant effects on nerve conduction velocity, endoneurial blood flow and oxygen tension in non-diabetic and streptozotocin-diabetic rats. Diabetologia 37: 449-459

106. Hallab M, Bled F, Ebran JM et al. (1992) Elevated serum angiotensin I converting enzyme activity in type 1, insulin-dependent diabetic subjects with persistent microalbuminuria. Acta Diabetol 29: 82-85

107. Takeda Y, Miyamori I, Yoneda T, Takeda R (1991) Production of endothelin-1 from the mesenteric arteries of streptozotocin-induced diabetic rats. Life Sci 48: 2553-2556

108. Takahashi K, Ghatei MA, Lam H-C, O'Halloran DJ, Bloom SR (1990) Elevated plasma endothelin levels in patients with diabetes mellitus. Diabetologia 33: 306-310

109. Ikeda K, Wada Y, Sanematsu H et al. (2001) Regulatory effect of experimental diabetes on the expression of endothelin receptor subtypes and their gene transcripts in the rat adrenal gland. J Endocrinol 168: 163-175

110. Jude EB, Abbott CA, Young MJ, Anderson SG, Douglas JT, Boulton AJM (1998) The potential role of cell adhesion molecules in the pathogenesis of diabetic neuropathy. Diabetologia 41: 330-336

111. Cameron NE, Cotter MA, Robertson S (1992) Angiotensin converting enzyme inhibition prevents the development of muscle and nerve dysfunction and stimulates angiogenesis in streptozotocin-diabetic rats. Diabetologia 35: $12-18$

112. Cameron NE, Dines KC, Cotter MA (1994) The potential contribution of endothelin-1 to neurovascular abnormalities in streptozotocin-diabetic rats. Diabetologia 37: 1209-1215

113. Cameron NE, Cotter MA (1996) Effects of a non-peptide endothelin-1 $\mathrm{ET}_{\mathrm{A}}$ antagonist on neurovascular function in diabetic rats: interaction with the renin-angiotensin system. J Pharmacol Exp Ther 278: 1262-1268

114. Cotter MA, Cameron NE (1998) Correction of neurovascular deficits in diabetic rats by $\mathrm{b}_{2}$ agonist and $\mathrm{a}_{1}$ adrenoceptor antagonist treatment: interactions with the nitric oxide system. Eur J Pharmacol 343: 217-223

115. Obrosova IG, Van Huysen C, Fathallah L, Cao X, Stevens M, Greene D (2000) Evaluation of $\alpha_{1}$-adrenoceptor antagonist on diabetes-induced changes in peripheral nerve 
function, metabolism, and antioxidative defense. FASEB J 14: 1548-1558

116. Robertson S, Cameron NE, Cotter MA (1992) The effect of the calcium antagonist nifedipine on peripheral nerve function in streptozotocin-diabetic rats. Diabetologia 35: 1113-1117

117. Kapelle AC, Bravenboer B, van Buren T, Traber J, Erkelens DW, Gispen WH (1993) Amelioration by the $\mathrm{Ca}^{2+}$ antagonist, nimodipine, on an existing neuropathy in the streptozotocin-induced, diabetic rat. Br J Pharmacol 108: 780-785

118. Hotta N, Koh N, Sakakibara F et al. (1996) Effects of beraprost sodium and insulin on the electroretinogram, nerve conduction and nerve blood flow in rats with streptozotocin-induced diabetes. Diabetes 45: 361-366

119. Yasuda H, Sonobe M, Yamashita M et al. (1989) Effect of prostaglandin $\mathrm{E}_{1}$ analogue TFC 612 on diabetic neuropathy in streptozocin-induced diabetic rats comparison with aldose reductase inhibitor ONO 2235. Diabetes 38: 832-838

120. Cameron NE, Cotter MA (1995) Effects of chronic treatment with a nitric oxide donor on nerve conduction abnormalities and endoneurial blood flow in streptozotocin-diabetic rats. Eur J Clin Invest 25: 19-24

121. Hohman TC, Cotter MA, Cameron NE (2000) ATP-sensitive $\mathrm{K}^{+}$channel effects on nerve function, $\mathrm{Na}^{+}, \mathrm{K}^{+}$ATPase, and glutathione in diabetic rats. Eur J Pharmacol 397: 335-341

122. Kihara M, Schmelzer JD, Low PA (1995) Effect of cilostazol on experimental diabetic neuropathy in the rat. Diabetologia 38: 914-918

123. Yamamoto Y, Yasuda Y, Kimura Y, Komiya Y (1998) Effects of cilostazol, an antiplatelet agent, on axonal regeneration following nerve injury in diabetic rats. Eur J Pharmacol 352: 171-178

124. Jarvis MF, Wessale JL, Zhu CZ et al. (2000) ABT-627, an endothelin $\mathrm{ET}_{\mathrm{A}}$ receptor-selective antagonist, attenuates tactile allodynia in a diabetic rat model of neuropathic pain. Eur J Pharmacol 388: 29-35

125. Greene DA, Sima AAF, Stevens MJ, Feldman EL, Lattimer SA (1992) Complications: neuropathy, pathogenetic considerations. Diabetes Care 15: 1902-1925

126. Baynes JW, Thorpe SR (1999) Role of oxidative stress in diabetic complications: a new perspective on an old paradigm. Diabetes 48: 1-9

127. Wolff SP (1993) Diabetes mellitus and free radicals. Br Med Bull 49: 642-652

128. Low PA, Nickander KK, Tritschler HJ (1997) The roles of oxidative stress and antioxidant treatment in experimental diabetic neuropathy. Diabetes 46 [Suppl 2]: S38-S42

129. Cameron NE, Cotter MA (1999) Effects of antioxidants on nerve and vascular dysfunction in experimental diabetes. Diabetes Res Clin Pract 45: 137-146

130. Loven DH, Schedl H, Wilson H et al. (1986) Effects of insulin and oral glutathione on glutathione levels and superoxide dismutase activities in organs of rats with streptozotocin-induced diabetes. Diabetes 35: 503-507

131. Soriano FG, Virag L, Jagtap P et al. (2001) Diabetic endothelial dysfunction: the role of poly(ADP-ribose) polymerase activation. Nature Med 7: 108-113

132. Lyall F, Gibson JL, Greer IA, Brockman DE, Eis ALW, Myatt L (1998) Increased nitrotyrosine in the diabetic placenta - Evidence for oxidative stress. Diabetes Care 21: 1753-1758

133. Du XL, Stockklauser-Faber K, Rösen P (1999) Generation of reactive oxygen intermediates, activation of NFkappa B, and induction of apoptosis in human endothelial cells by glucose: Role of nitric oxide synthase? Free Radic Biol Med 27: 752-763

134. Beckman JS, Beckman TW, Chen J, Marshall PA, Freeman BA (1990) Apparent hydroxyl radical production by peroxynitrite: implications for endothelial injury from nitric oxide and superoxide. Proc Natl Acad Sci USA 87: 1620-1624

135. Keegan A, Walbank H, Cotter MA, Cameron NE (1995) Chronic vitamin E treatment prevents defective endothelium relaxation in diabetic rat aorta. Diabetologia 38: $1475-1478$

136. Rossen P, Ballhausen T, Bloch W, Addicks K (1995) Endothelial relaxation is disturbed by oxidative stress in the diabetic rat heart: influence of tocopherol as antioxidant. Diabetologia 38: 1157-1168

137. Archibald V, Cotter MA, Keegan A, Cameron NE (1996) Contraction and relaxation of aortas from diabetic rats: effects of chronic anti-oxidant and aminoguanidine treatments. Naunyn-Schmeideberg's Arch. Pharmacol 353: 584-591

138. Timimi FK, Ting HH, Haley EA, Roddy MA, Ganz P, Creager MA (1998) Vitamin C improves endothelium-dependent vasodilation in patients with insulin-dependent diabetes mellitus. J Am Coll Cardiol 31: 552-557

139. Jack A, Cotter MA, Cameron NE (1998) Impaired endothelium-derived hyperpolarizing factor in the mesenteric vasculature of diabetic rats: effects of antioxidant treatment. Diabetic Med 15 [Suppl 1]: S31 (Abstract)

140. Nagamatsu M, Nickander KK, Schmelzer JD et al. (1995) Lipoic acid improves nerve blood flow, reduces oxidative stress and improves distal nerve conduction in experimental diabetic neuropathy. Diabetes Care 18: 1160-1167

141. Cotter MA, Love A, Watt MJ, Cameron NE, Dines KC (1995) Effects of natural free radical scavengers on peripheral nerve and neurovascular function in diabetic rats. Diabetologia 38: 1285-1294

142. Cameron NE, Cotter MA, Horrobin DH, Tritschler HJ (1998) Effects of $\alpha$-lipoic acid on neurovascular function in diabetic rats: interaction with essential fatty acids. Diabetologia 41: 390-399

143. Sagara M, Satoh J, Wada R et al. (1996) Inhibition of development of peripheral neuropathy in streptozotocin-induced diabetic rats with n-acetylcysteine. Diabetologia 39: 263-269

144. Love A, Cotter MA, Cameron NE (1997) Effects of $\alpha$-tocopherol on nerve conduction velocity and regeneration following a freeze lesion in immature diabetic rats. Naunyn-Schmeideberg's Arch Pharmacol 355: 126-130

145. Keegan A, Cotter MA, Cameron NE (1999) Effect of diabetes and treatment with the antioxidant, $\alpha$-lipoic acid, on endothelial and neurogenic responses of corpus cavernosum in rats. Diabetologia 42: 343-350

146. Pieper GM, Dembny K, Siebeneich W (1998) Long-term treatment in vivo with NOX-101, a scavenger of nitric oxide, prevents diabetes-induced endothelial dysfunction. Diabetologia 41: 1220-1226

147. Cellek S, Rodrigo J, Lobos E, Fernandez P, Serrano J, Moncada S (1999) Selective nitrergic neurodegeneration in diabetes mellitus - a nitric oxide-dependent phenomenon. Br J Pharmacol 128: 1804-1812

148. Cameron NE, Cotter MA (1996) Rapid reversal by aminoguanidine of the neurovascular effects of diabetes in rats: modulation by nitric oxide synthase inhibition. Metabolism 45: 1147-1152 149

149. Cameron NE, Cotter MA, Hohman TC (1996) Interactions between essential fatty acid, prostanoid, polyol path- 
way and nitric oxide mechanisms in the neurovascular deficit of diabetic rats. Diabetologia 39: 172-182

150. Cameron NE, Cotter MA, Jack AM, Basso MD, Hohman TC (1999) Protein kinase C effects on nerve function, perfusion, $\mathrm{Na}^{+}, \mathrm{K}^{+}$-ATPase activity and glutathione content in diabetic rats. Diabetologia 42: 1120-1130151

151. Morel DW, Chisolm G (1989) Antioxidant treatment of diabetic rats inhibits lipoprotein oxidation and cytotoxicity. J Lipid Res 30: 1827-1834

152. Watts GF, O'Brien SF, Silvester W, Millar JA (1996) Impaired endothelium-dependent and -independent dilatation of forearm resistance arteries in men with diet-treated non-insulin-dependent diabetes: role of dyslipidaemia. Clin Sci (Colch) 91: 567-573

153. Kamata K, Sugiura M, Kojima S, Kasuya Y (1996) Preservation of endothelium-dependent relaxation in cholesterol-fed and streptozotocin-induced diabetic mice by the chronic administration of cholestyramine. Br J Pharmacol 118: 385-391

154. Cameron NE, Smith G, Mactaggart F, Cotter MA (2000) Effects of treatment with the statin, ZD4522, on peripheral nerve function and perfusion in diabetic rats. Diabetologia 43 [Suppl 1]: A50 (Abstract)

155. Failla ML, Kiser RA (1981) Altered tissue content and cytosol distribution of trace metals in experimental diabetes. J Nut 111: 1900-1909

156. Walter RM Jr, Uriu-Hare JY, Olin KL et al. (1991) Copper, zinc, manganese, and magnesium status and complications of diabetes mellitus. Diabetes Care 14: 1050-1056

157. Cameron NE, Cotter MA (1995) Neurovascular deficits in diabetic rats: potential contribution of autoxidation and free radicals examined using transition metal chelating agents J Clin Invest 96: 1159-1163

158. Keegan A, Cotter MA, Cameron NE (1999) Effects of chelator treatment on aorta and corpus cavernosum from diabetic rats. Free Radic Biol Med 27: 536-543

159. Cameron NE, Cotter MA (2001) Effects of an extracellular metal chelator on neurovascular function in diabetic rats. Diabetologia 44: 621-628

160. Zeigler D, Hanefield M, Ruhnau KJ et al. (1999) Treatment of symptomatic diabetic polyneuropathy with the antioxidant alpha-lipoic acid: a 7-month multicenter randomized controlled trial (ALADIN III Study). ALADIN III Study Group. Alpha-Lipoic Acid in Diabetic Neuropathy. Diabetes Care 22: 1296-1301

161. Bucala R, Cerami A, Vlassara H (1995) Advanced glycosylation end products in diabetic complications. Biochemical basis and prospects for therapeutic intervention. Diabetes Rev 3: 258-268

162. Saxena AK, Saxena P, Wu X, Obrenovich M, Weiss MF, Monnier VM (1999) Protein aging by carboxymethylation of lysines generates sites for divalent metal and redox active copper binding: Relevance to diseases of glycoxidative stress. Biochem Biophys Res Commun 260: 332-338

163. Yu PH, Zuo DM (1997) Aminoguanidine inhibits semicarbazide-sensitive amine oxidase activity: implications for advanced glycation and diabetic complications. Diabetologia 40: 1243-1250

164. Hotta N (1995) New approaches for treatment in diabetes: aldose reductase inhibitors. Biomed Pharmacother 49: 232-243

165. Efanova I (1999) Minalrestat. Curr Opin Oncol Endocrin Metab Investigational Drugs 1: 101-107
166. Greene DA, Arezzo JC, Brown MB (1999) Effect of aldose reductase inhibition on nerve conduction and morphometry in diabetic neuropathy. Zenarestat Study Group. Neurology 53: 580-591

167. Cameron NE, Cotter MA, Dines KC, Maxfield EK, Carey F, Mirlees DJ (1994) Aldose reductase inhibition, nerve perfusion, oxygenation and function in streptozotocin-diabetic rats: dose-response considerations and independence from a myo-inositol mechanism. Diabetologia 37: 651-66168. 168.

Obrosova IG, Fathallah L, Lang HJ, Greene DA (1999) Evaluation of a sorbitol dehydrogenase inhibitor on diabetic peripheral nerve metabolism: a preventive study. Diabetologia 42: 1187-1194

169. Jiang ZY, Zhou QL, Eaton JW, Koppenol WH, Hunt JV, Wolff SP (1991) Spirohydantoin inhibitors of aldose reductase inhibit iron-catalyzed and copper catalyzed ascorbate oxidation in vitro. Biochem Pharmacol 42: 1273-1278

170. Cameron NE, Cotter MA, Basso M, Hohman TC (1997) Comparison of the effects of inhibitors of aldose reductase and sorbitol dehydrogenase on neurovascular function, nerve conduction and tissue polyol pathway metabolites in streptozotocin-diabetic rats. Diabetologia 40: 271-281

171. Schmidt RE, Dorsey DA, Beaudet LN, Plurad SB, Williamson JR, Ido Y (1998) Effect of sorbitol dehydrogenase inhibition on experimental diabetic autonomic neuropathy. J Neuropathol Exp Neurol 57: 1175-1189

172. Koya D, King GL (1998) Protein kinase C activation and the development of diabetic complications. Diabetes 47: 859-866

173. Nakamura J, Kato K, Hamada Y et al. (1999) A protein kinase C-beta-selective inhibitor ameliorates neural dysfunction in streptozotocin-induced diabetic rats. Diabetes 48: 2090-2095

174. Jack AM, Cameron NE, Cotter MA (1999) Effects of the diacylglycerol complexing agent, cremophor, on nerve conduction velocity and perfusion in diabetic rats. J Diabetes Complications 13: 2-9

175. Jack A, Cotter MA, Cameron NE (1999) Treatment with the protein kinase $C \beta$ inhibitor, LY333531, attenuates the development of impaired endothelium-dependent vasodilatation in the mesenteric vasculature of diabetic rats. Diabetes 48 [Suppl 1]: A130 (Abstract)

176. Cameron NE, Cotter MA (1999) Role of linolenic acid in diabetic polyneuropathy. In: Dyck PJ, Thomas PK (eds) Diabetic Neuropathy, 2nd edn. Saunders, Philadelphia pp 359-367

177. Cotter MA, Cameron NE (1997) Effects of dietary supplementation with arachidonic acid rich oils on nerve conduction and blood flow in streptozotocin-diabetic rats. Prostaglandins Leukot Essent Fatty Acids 56: 337-343

178. Jack A, Cotter MA, Cameron NE (2000) Essential fatty acid effects on endothelium dependent relaxation in the mesenteric vascular bed of diabetic and nondiabetic rats. Diabetes 49 [Suppl 1]:A54 (Abstract)

179. Fissithaler B, Popp R, Kiss L et al. (1999) Cytochrome $\mathrm{P} 4502 \mathrm{C}$ is an EDHF synthase in coronary arteries. Nature 401: 493-496

180. Cameron NE, Cotter MA (1996) Comparison of the effects of ascorbyl $\gamma$-linolenic acid and $\gamma$-linolenic acid in the correction of neurovascular deficits in diabetic rats. Diabetologia 39: 1047-1054 